\title{
内质网靶向型有机小分子荧光探针的研究进展
}

\author{
张晟曦 ${ }^{a}$ 牛晴旻 ${ }^{a}$ 吴松泽 ${ }^{b}$ 吕海娟 ${ }^{a}$ 邢国文 ${ }^{*, a}$ \\ ( ${ }^{a}$ 北京师范大学化学学院 北京 100875) \\ $\left({ }^{b}\right.$ 中国人民大学附属中学 北京 100080)
}

\begin{abstract}
摘要 内质网是真核细胞中重要的细胞器, 参与多种蛋白质、糖原、脂类及胆固醇类物质的合成和分泌. 内质网由细 胞质中单层膜包围而成, 具有由扁平膜囊、膜管以及膜泡相连形成的三维网状结构. 对内质网生理形态的研究有助于 攻克某些代谢疾病. 荧光探针技术在细胞器定位方面由于其光学性质良好, 特异性定位效果突出, 广泛地用于细胞器 的结构探究和活动追踪. 内质网荧光探针可分为两类: 一类是单功能的内质网定位探针; 另一类是多功能内质网探针, 具有定位和检测内质网中活性物种、内质网形态和环境的多重功能. 总结与评述了近年来重要的内质网探针的结构、 功能和生物应用, 阐述了内质网荧光探针多样的定位机理, 展望了内质网荧光探针在生命科学研究领域的发展趋势. 关键词 内质网; 苂光探针; 靶向定位; 多功能探针
\end{abstract}

\section{Recent Progress on Endoplasmic Reticulum-Targetable Small Organic Fluorescent Probes}

\author{
Zhang, Shengxi $^{a} \quad \mathrm{Niu}$ Qingmin $^{a} \quad \mathrm{Wu}$, Songze $^{b} \quad$ Lü, Haijuan $^{a} \quad$ Xing, Guowen ${ }^{*, a}$ \\ ( ${ }^{a}$ College of Chemistry, Beijing Normal University, Beijing 100875) \\ ( ${ }^{b}$ The High School Affiliated to Renmin University of China, Beijing 100080)
}

\begin{abstract}
Endoplasmic reticulum (ER) is an important organelle in eukaryotic cells and participates in the synthesis and secretion of various proteins, glycogen, lipids, and cholesterol substances. It is surrounded by a single membrane in the cytoplasm, which is a three-dimensional mesh structure formed by flat cysts, membrane tubes, and bubbles. Research on the physiological morphology of ER can facilitate the resolution of certain metabolic diseases. Due to the good optical properties and outstanding specific localization, fluorescent probe technology has been widely used in structural investigation and activity tracking of organelles. The ER fluorescent probes can be divided into two types, one is a single functional ER localization probe, the other is a multi-functional ER probe, which has multiple functions of locating and detecting active species in ER, the morphology and environment of ER. In this article, the structure, function and biological application of ER fluorescent probes in recent years are summarized and reviewed. Various localization mechanisms of ER fluorescent probes are described. The development trend of ER fluorescent probes in life science research is prospected.
\end{abstract}

Keywords endoplasmic reticulum; fluorescent probe; targetable localization; multi-functional probe

内质网膜属于生物膜系统, 广泛存在于真核细胞 中, 其面积在动物细胞的膜系统总面积中占比至少达到 一半. 按照内质网膜上核糖体的有无可分为粗面内质网 和滑面内质网 ${ }^{[1]}$. 粗面内质网上具有大量核糖体, 是分 泌性蛋白、溶酶体蛋白和膜蛋白合成、加工、分选的场 所; 而滑面内质网则没有核糖体, 是脂类物质等的合成 场所; 内质网内腔则是重要的钙离子储存场所. 蛋白质 在内质网腔内发生折叠修饰, 被释放到细胞的其他细胞
器中或者被排出细胞 ${ }^{[2]}$. 钾离子通道是一种内质网膜上 广泛存在的功能蛋白, 是钾离子进出细胞的通道, 起到 稳定静息膜电位、调节动作电位幅值、时程和发生频率、 影响囊泡分泌的作用.一些外界诱因如缺氧, 病毒感染, 氧化还原作用, 葡萄糖的缺失等会影响到蛋白质的折 叠. 未折叠或折叠错误的蛋白质聚集在内质网腔内会影 响内质网正常生理作用, 从而引发内质网功能的内稳态 失衡, 导致内质网应激 ${ }^{[3,4]}$. 内质网应激是一种亚细胞的

* Corresponding author. E-mail: gwxing@bnu.edu.cn

Received October 18, 2018; revised December 12, 2018; published online December 28, 2018.

Project supported by the National Natural Science Foundation of China (No. 21272027).

国家自然科学基金(No. 21272027)资助项目. 
病理状态, 严重的内质网应激会引起细胞调亡. 大量研 究表明内质网应激会导致呼吸道以及心血管炎症、自身 免疫病、代谢病、糖尿病、老年性痴呆甚至癌症等疾病 的发生 ${ }^{[5]}$. 由于内质网的状态和结构是动态的, 受环境 因素影响很大, 故内质网的实时成像对研究内质网的生 理学功能和病理学机制至关重要. 发展灵敏和专一性的 内质网探针, 通过定位研究内质网动力学, 分析内质网 应激过程中内质网内化学环境和物质的改变对攻克上 述疾病有重要的研究意义.

近年来, 活细胞内质网荧光成像研究发展迅速 ${ }^{[6]}$, 出现了很多商用内质网探针, 如最广泛使用的 $\mathrm{DiOC}_{6}$ (3,3'-dihexyloxacarbocyanine iodide)和 ER-Tracker 系列 等 ${ }^{[7]}$. 但这些市售商用探针可能会对正常细胞生理活动 产生影响, 且价格昂贵. 除此之外, 一些新型的内质网 苂光探针也被相继报道. 靶向内质网的新型荧光探针可 以分为两类, 第一类是单功能定位于内质网的探针, 主 要应用于内质网的活体成像; 第二类是多功能的定位检 测苂光探针, 此类探针不仅可以定位于内质网, 并且可 以检测内质网中的重要物种. 内质网探针的定位机理主 要有三种: 基于内质网代谢过程, 基于与内质网中特异 性物种结合, 以及基于内质网膜的脂溶性. 本综述对近 十年来重要的内质网荧光探针的结构、功能和生物应用 进行总结和评述.

\section{1 单功能内质网探针}

单功能内质网定位探针特异性地定位于内质网上 并且能够对其进行苂光成像, 通过对其形态和分布进行 观察, 从而研究相关的生理过程. 此类探针需要解决的 主要问题是, 如何对内质网进行特异性定位, 并且在定 位后不对内质网的正常生理功能产生影响.

\section{1 基于内质网代谢的荧光探针}

此类探针的定位机理是在构建探针的时候引入了 可以在内质网中代谢的基团，通过特定的生理过程使探 针进入内质网, 从而实现定位.

Villa 小组 ${ }^{[8]}$ 设计了一种以胆碱为定位基团的苂光 探针 1, 胆碱苂光衍生物 NBD-Choline. 实验发现在药 敏性肿瘤细胞(MCF-7)中, 该探针主要定位在内质网上, 这是因为胆碱在内质网中代谢. 而在耐药性肿瘤细胞 (MCF-7/DX)中的后续实验发现, 该探针定位到了高尔 基体, 可能的原因是耐药性癌细胞改变了胆碱的代谢途 径. 探针 1 的结构中 NBD 苂光团与胆碱氮原子上的一 个甲基相连, 该连接部位不会影响胆碱的生物功能, 保 证探针 1 可以正常在内质网中代谢, 从而实现定位功能.

哺乳动物体内的羧酸酯酶是一个大的同功酶家族. 其活性中心含丝氨酸残基, 能有效催化酯键和硫酯键的
水解 ${ }^{[9]}$. 羧酸酯酶存在于许多组织的内质网中, 其识别 底物特异性较低，只要底物中有酯键都可以被羧酸酯酶 水解. 据此, Hakamata 小组 ${ }^{[10]}$ 设计了一种酯保护的苂光 探针 2 , 探针进入细胞后在内质网中被水解, 并进一步 异构化断裂生成试卤灵(Resorufin)，从而产生苂光. 探 针本身在试卤灵的苂光波段并无荧光，不会干扰测定. 遗憾的是, 细胞质和线粒体中也存在少许羧酸酯酶, 可 能会干扰测定.<smiles>CCCC(=O)Oc1ccc(COc2ccc3nc4ccc(=O)cc-4oc3c2)cc1</smiles>

\section{2 与内质网特异性物种结合的荧光探针}

此类探针在构建分子结构的时候引入了一些可以 与内质网内蛋白，或者膜上的离子受体特异性结合的基 团, 当探针进入细胞后与这些物质结合从而实现定位.

市面上常见的内质网苂光探针 ER-Tracker 系列，包 括 ER-Tracker Red (3a), ER-Tracker Green (3b)以及 ER-Tracker Blue-White DPX (3c)等. 这些探针中氟嗍吡 咯(BODIPY)等荧光团与格列本脲相连. 格列本嫝可以 与内质网上广泛存在的钾离子通道中的磺嫝受体结合,

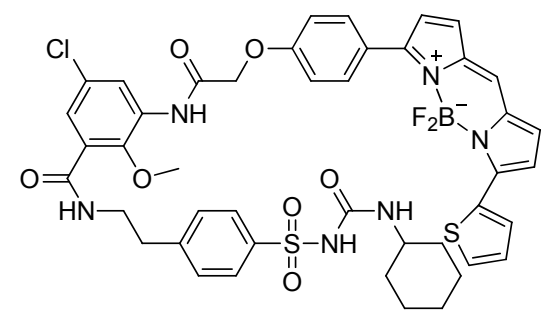

$3 a$

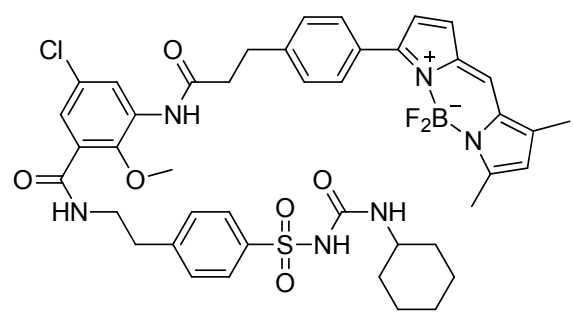

3b

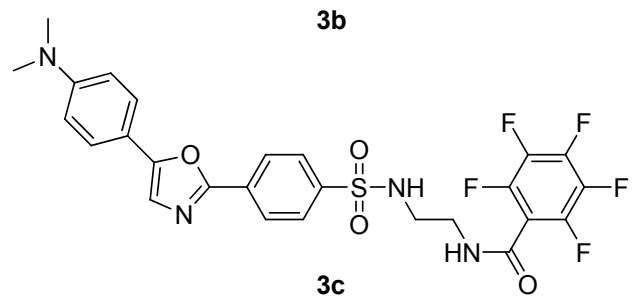


从而实现定位. 最近, 彭孝军小组 ${ }^{[11]}$ 设计了一种可以定 位于内质网膜的双光子苂光探针 $\mathbf{4}$, 此探针背景辐射低, 不会对内质网正常生理活动产生影响, 氯原子官能团的 存在实现了其与内质网上氯离子录的特异性结合, 从而 完成了对内质网的定位.

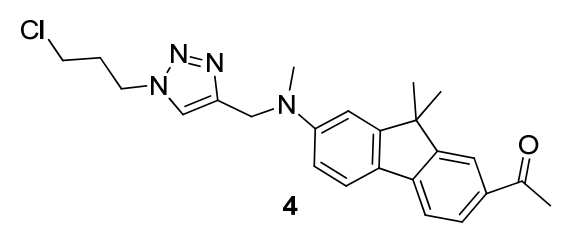

McDonald 小组 ${ }^{[12]}$ 将黄酮衍生物进行结构修饰后实 现了其与内质网中特异性蛋白结合的功能. 黄酮衍生物 荧光探针 $5 \mathbf{a}$ 和 $\mathbf{5 b}$ 的发光机理是基于激发态分子内的质 子转移(Excited State Intramolecular Proton Transfer, ESIPT). 此类探针分子结构中含有取代氨基和酰胺基 团, 分别作为电子给体和电子受体, 探针 $\mathbf{5}$ 在水溶液中 无荧光发射, 与内质网中的某些蛋白结合后会发射荧 光. 探针 5a 吸收峰和发射峰分别为 $406,495 / 570 \mathrm{~nm}$, 探 针 5b 吸收峰和发射峰为 $411,536 / 587 \mathrm{~nm}$. 这两个探针 拥有两个发射波长的原因是他们存在两个 ESIPT 互变 异构体(图 1).

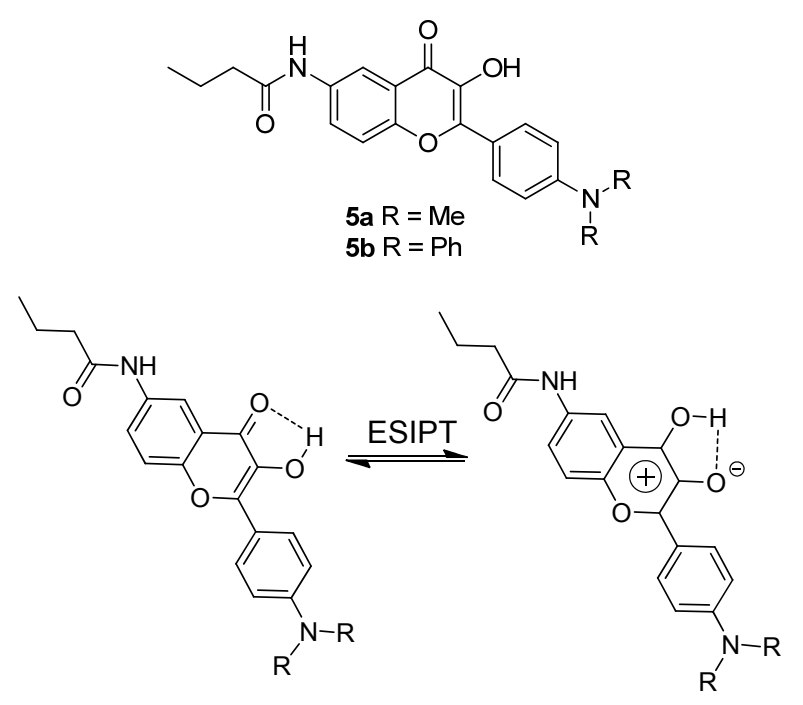

图 1 探针 5 的互变异构

Figure 1 The tautomerism of probe 5

Liu 小组 ${ }^{[13]}$ 设计合成了基于聚集诱导发光效应 (AIE)的探针 $6 \mathbf{a}$ (NTPE-DCV). 该探针以二甲氨基和二 㲵基乙烯基(DCV)分别为电子给体和电子受体，其光稳 定性好, 在波长大于 $500 \mathrm{~nm}$ 的范围内具有很高的摩尔 吸收系数. 但是 $\mathbf{6 a}$ 中的 DCV 基团会与不同的生物硫醇 反应，会对内质网成像造成干扰. 将 DCV 的一个氰基 改变为酰胺基团后, 得到的探针 $\mathbf{6 b}$ 的苂光强度增加了 57 倍, 还彻底地消除了与生物硫醇的反应. KDEL 是一 个内质网靶向肽, 将此肽连接到酰胺化的探针后, 可以 灵敏地定位到内质网上. 为了进一步提高探针定位的灵 敏性, 该小组将一个具有马来酰亚胺的 NTPE-DCV 衍 生物与 KDEL 连接在一起, 得到了探针 7 .<smiles>[R]C(C#N)=Cc1ccc(C(=C(c2ccccc2)c2ccc(N(C)C)cc2)c2ccc(N(C)C)cc2)cc1</smiles>

6a, $\mathrm{R}=\mathrm{CN}$<smiles></smiles>

\section{3 基于内质网膜脂溶性的荧光探针}

内质网膜和细胞膜一样是一个良好的脂溶性系统, 根据相似相溶原理, 良好的脂溶性探针可能会溶解在内 质网膜上. 基于此原理, 许多文献报道了多种拥有良好 脂溶性的苂光探针, 用以定位内质网. 最早使用的该类 内质网荧光探针有 $\mathrm{DiOC}_{6}(\mathbf{8})$ 和 $\mathrm{DiOC}_{5}(\mathbf{9})$ 等, 这些探针 多是偏脂溶性, 定位机理主要是利用探针的亲脂性以及 自身所带的正电荷来灵敏地定位于脂溶性好且膜电势

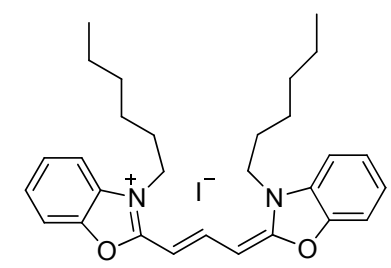

8

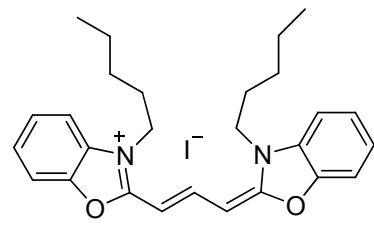

9<smiles>C/C(=C\c1ccc(/C(=C(\c2ccccc2)c2ccc(N(C)C)cc2)c2ccc(N(C)C)cc2)cc1)C(=O)N(C)CCCN1C(=O)CC(SC[C@H](NC(=O)[O-])C(=O)N[C@@H](Cc2ccccc2)C(=O)N[C@@H](Cc2ccccc2)C(=O)N[C@@H](CCCCN)C(=O)N[C@@H](CC(=O)O)C(=O)N[C@@H](CCC(=O)O)C(=O)NC(CC(C)C)C(=O)O)C1=O</smiles> 
高的内质网上. 这类探针由多环的荧光团和烷基疏水链 组成, 能够穿透质膜. 当探针浓度较高时, 会聚集在内 质网中, 并在膜内自由扩散, 从而分散到连续的膜上, 显示出膜的形状. 但该类型探针对内质网特异性不强, 有时会扩散到其他膜上.

Peterson 小组 ${ }^{[14]}$ 设计了一个含有长疏水基团的试卤 灵的氨基类似物 10 为内质网探针, 以试卤灵为原料, 两 步即可制得. 其吸收峰和发射峰为 565 和 $614 \mathrm{~nm}$, 量子 产率 0.7 .

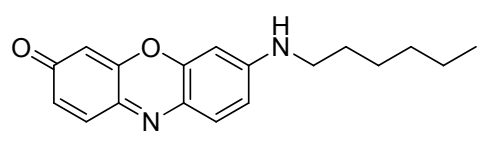

10

Meinig 等 ${ }^{[15]}$ 设计了两种探针, 一种利用了内质网 的脂溶性实现定位(11a), 另一种通过添加一个特异性 基团来和内质网中的 $\mathrm{p} 97$ 蛋白特异性结合实现定位 (11b). 11a 和 $11 \mathrm{~b}$ 都属于氨基酚的衍生物, 且侧链的修饰 不会影响到其苂光性质. 共定位实验表明该探针可以定 位于内质网(图 2). 两种探针量子产率为 0.85 , 吸收峰和 发射峰分别为 512 和 $532 \mathrm{~nm}$.<smiles>COCCNc1cc2oc3cc(=O)c(F)cc-3c(-c3ccccc3C)c2cc1F</smiles><smiles></smiles>

Collot 小组 ${ }^{[16]}$ 基于方酸染料设计了近红外内质网苂 光探针 12a, 12b. 该探针由方酸苂光团、长烷基链(用以 针定于疏水膜)和两性离子基团(通过亲水疏水作用在膜 表面稳定探针)组成. 由于细胞膜也是疏水脂溶性系统, 该探针可能也会针定在细胞膜上.

探针 13a 中的芳基取代的氮杂氟嗍苂(Aza-BODIPY)部分疏水性很强, 会无选择性地聚集在细胞疏水膜 上, 无法用于细胞内研究. 为解决此问题, 在此芳基氮 杂氟硼荧上引入多醚取代基, 使其水溶性增加, 从而可 以渗透进细胞 ${ }^{[17]}$. Burgess 小组合成了四种探针 13b $13 \mathrm{e}$, 此类探针既有合适的水溶性可以通过细胞膜, 又 有适当的脂溶性可以定位于内质网.

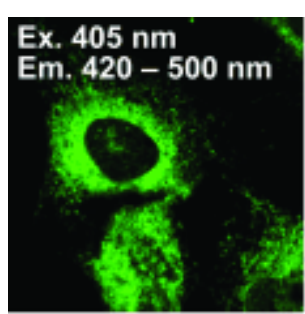

Ex. $488 \mathrm{~nm}$
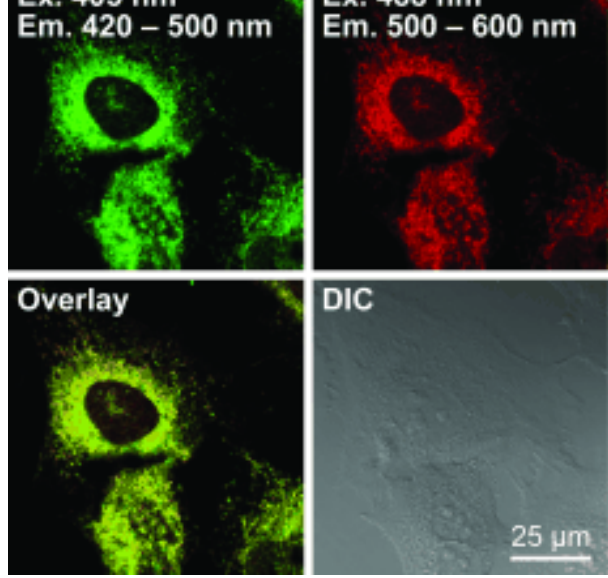

图 2 探针 11a 定位于内质网的共聚焦激光扫描图像 ${ }^{[15]}$

Figure 2 Confocal laser scanning and differential interference contrast (DIC) micrographs of living HeLa cells treated with ER-tracker Blue-White DPX and 11a.
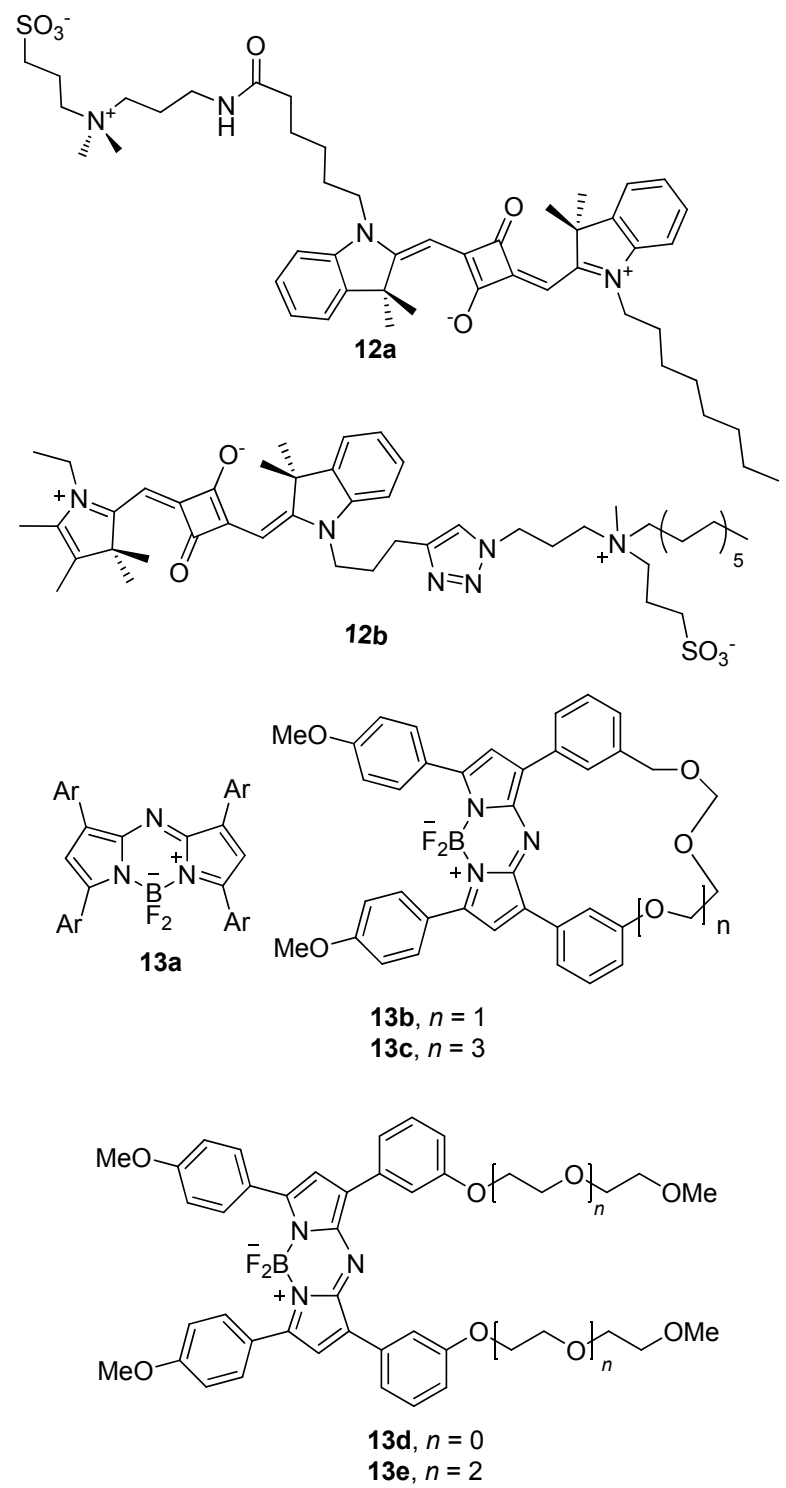
$\mathrm{Kim}$ 小组 ${ }^{[18]}$ 基于三价铱络合物合成了两种可以对 DNA 和内质网进行定位的探针 14. 体外实验表明 14 可 与 DNA 发生疏水作用, 从而与 DNA 特异结合, 也可以 与脂膜发生疏水作用而特异性定位到脂膜上. 探针在细 胞内很难定位到细胞核中的 DNA 上, 这是因为 DNA 处 于染色体内, 并没有裸露出来. 与 ER-Tracker 共定位实 验发现, 此探针可以定位于内质网, 定位机理是探针 $\mathbf{1 4}$ 与膜发生疏水作用从而完成定位.
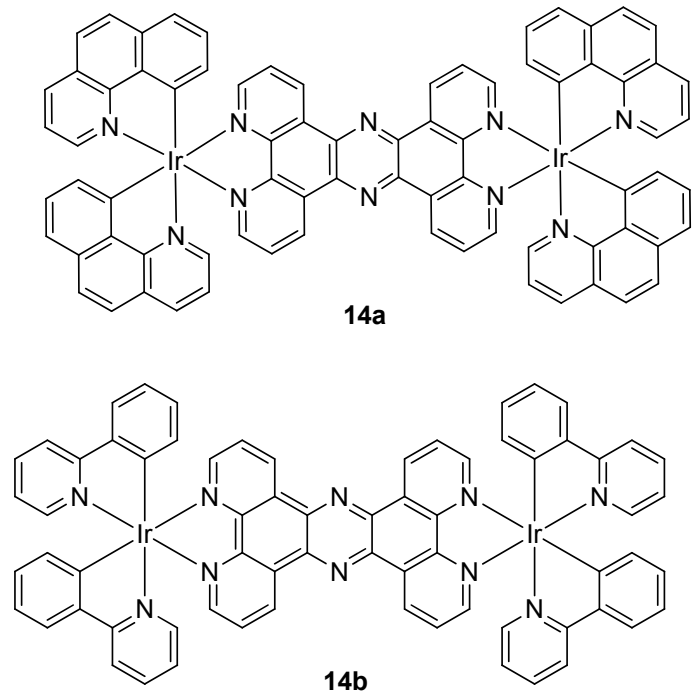

\section{4 其他定位机理的荧光探针}

Kim 小组 ${ }^{[19]}$ 设计的一种双光子荧光探针 15 (ELP1), 可以用于观察活细胞内从内质网到溶酶体的细胞内囊 泡转移. 该探针无 $\mathrm{pH}$ 依赖性, 具有良好的水溶性、低细 胞毒性和高细胞负载能力. 成像实验表明, 此探针最初 定位于内质网, 然后转移到溶酶体隔室. 因此这个探针 可以作为实时研究与细胞运输有关生理过程的有效工 具. 榺基和甲基氨基可能使得探针 15 定位在内质网上.

一些内质网定位探针的设计利用了非天然氨基酸 标记蛋白质技术，通过可以发射苂光的氨基酸小分子嵌 入目标蛋白实现定位. Schultz 小组 ${ }^{[20]}$ 设计了一种氨基酸 衍生物探针 16, 该探针体积较小, 不会影响目标蛋白质 的正常生理功能. 探针 16 对环境敏感, 会随微环境的变 化而改变其发射峰位置和强度, 用以研究蛋白质构象变 化和分子间相互作用. 共定位实验显示, 该探针可以对 细胞核、内质网和高尔基体染色，可能的机理是，其可
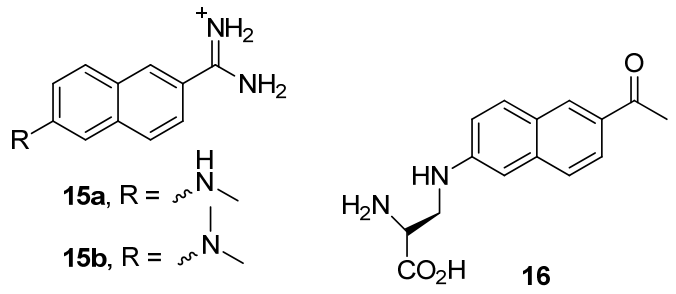

以通过非天然氨基酸标记蛋白，从而使其嵌入到内质网 中蛋白质的特定位点.

\section{2 多功能内质网探针}

除了单功能的内质网定位探针, 许多多功能探针也 被报道. 此类探针不仅实现了对内质网的定位，而且也 可以检测内质网的形态以及内质网中重要活性物种, 大 致可以分为如下几类: 检测内质网中的特定活性物种、 检测内质网形态和检测内质网内的化学环境.

\section{1 检测内质网中的活性物种}

主要包括对金属离子、活性氧物种(Reactive Oxygen Species, ROS)、活性氮物种(Reactive Nitrogen Species, RNS)以及酶等的检测.

\subsection{1 检测金属离子}

锌离子是动物体内一种非常重要的金属阳离子, 在所有动物的生息繁衍中起到非常重要的作用. 锌离子 是重要的催化中心, 参与许多辅酶结构的构建. 锌离子 在细胞调亡、基因表达、神经信号发射与调节、酶的调 控中起非常重要的作用. 锌离子的失调也会导致如局部 缺血、帕金森综合征、癫㾁以及某些类型的癌症等疾病 的发生 ${ }^{[21]}$. 此外, 锌离子在许多植物体内也参与很多重 要的生理过程, 锌离子的不足会严重影响某些植物的光 合作用. 因此, 发展细胞水平的锌离子分析检测技术至 关重要的.

Zhang 小组 ${ }^{[2]}$ 设计的探针 $\mathbf{1 7}$ 以苯并噻唑为荧光团, Schiff 碱为识别基团, 整个分子构成了一个大的共轭体 系. 根据软硬酸碱理论, 此 Schiff 碱可以与锌离子特异 性结合, 形成分子内光诱导电子转移体系, 用以检测锌 离子. 探针 17 对锌离子的检测极限是 $5.8 \mathrm{nmol} / \mathrm{L}$, 此检 测限足以在生物体系应用. 该探针在相同浓度下只对锌 离子有特异性，对其他金属离子甚至是与锌类似的镉皆 无响应，但高浓度的其他金属离子会导致荧光猝灭. 探 针 17 的定位机理是利用了其自身的疏水性，用 ER-Tracker 共定位实验表明其可以定位在内质网上. Lippard 小组 ${ }^{[23,24]}$ 以苯并试卤灵荧光团为基础，以吡啶 甲基胺或其类似物为锌离子识别基团，构建了锌离子探 针 18a 18d. 该类探针与锌离子结合前后发射波长不 同，可以用来检测锌离子的存在. 其定位机理是过氧亚 硝酰 $\left(\mathrm{ONOO}^{-}\right)$刺激内质网产生压力应激, 使内质网释放 出锌离子，探针与锌离子结合便可定位于内质网上. 依 据此机理，也可以用此探针间接检测内质网中的一氧化 氮的存在.

铁离子是细胞中的必需微量元素, 在蛋白质中以辅 助因子的形式存在, 参与了众多重要的生理过程, 如氧 气的运输、线粒体内的电子转移以及生物基质的氧化还 
原等. 然而, 自由存在的铁离子对细胞可能有潜在的毒 性, 会产生活性氧物种, 对细胞造成氧化损伤. 实际上, 含铁蛋白释放铁离子会引起很多神经退行性疾病 ${ }^{[25]}$. 检测活细胞中铁离子, 对了解其毒性以及与人类疾病的 关系有重要意义.<smiles>CN(C)c1ccc(C=Nc2ccc(-c3nc4ccccc4s3)cc2)c(O)c1</smiles><smiles>[Y]c1cc(N=C2C(O)=C(Br)C(=O)c3ccccc32)cc(CN(Cc2cccnc2)Cc2ccccn2)c1O</smiles>

Lee 小组 ${ }^{[26]}$ 合成出了几种罗丹明衍生的 Schiff 碱探 针, 可以特异性检测细胞内的三价铁离子. 三价铁离子 可以使 Schiff 碱水解开环, 使罗丹明的苂光恢复. 通过 线粒体、溶酶体和内质网的市售探针的共定位实验, 发 现这一系列探针主要定位于内质网. 在这些探针中, 化 合物 19 定位最灵敏, Person 系数为 0.78. 该探针对三价 铁专一性高, 仅有二价录离子会干扰苂光, 而其他金属 离子产生的影响可忽略. 该探针吸收峰和发射峰的强度 随三价铁浓度的上升而增强, 据此可以区分正常细胞和 铁过量细胞.

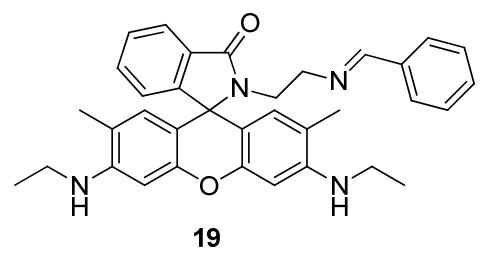

铜在众多生化过程中, 如呼吸作用、电子和氧气的 转移、活性氧物种的减少和神经递质的合成及代谢等生 理过程起到重要作用. 铜元素含量在细胞中的失常与许 多人类疾病, 如门克氏病、威尔逊氏病、阿尔茨海默氏 病和帕金森病等密切相关. 监控亚细胞组织中铜含量变 化对疾病的检测和预防有重大意义.

Kang 等 ${ }^{[27]}$ 设计合成了一系列活体细胞器选择性检 测铜离子的比率荧光探针 20. 该探针是连接了酰肼基 团的荎二甲酰亚胺. 酰肼基团易被二价铜离子水解, 释 放出荎二甲酰亚胺苂光团, 产生分子内电荷转移 (Intramolecular Charge Transfer, ICT), 从而对细胞内的 铜离子产生比率响应. 探针分子 $20 a, 20 b$ 具有生物相容
性，选择性定位在活细胞的内质网上，在铜超载的生物 环境中被铜离子催化水解, 该过程伴随苂光比率变化. 探针 20a 具有较宽的吸收带和发射带, 两者峰值分别为 380 和 $480 \mathrm{~nm}$. 添加铜离子后, 20a 的吸收峰值从 $380 \mathrm{~nm}$ 变为 $440 \mathrm{~nm}$, 其颜色从无色变为黄色; 相应地, 荧光颜 色从蓝色变为黄绿色, 发射峰从 $480 \mathrm{~nm}$ 变为 $545 \mathrm{~nm}$. 加入其它金属离子后, 没有观察到这些变化. 探针 $20 \mathrm{~b}$ 的表现和 20a 相似，探针与其他生物金属不反应，对铜 离子有高度选择性. 共定位实验显示其对内质网有良好 的选择性.

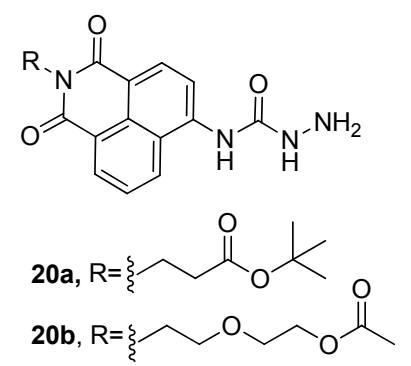

\section{1 .2 检测活性氧物种}

次氯酸根是一种活性氧物种, 一般在生物体的弱碱 性环境下生成. 次氯酸根在活细胞的生化过程中起重要 作用，比如抵抗微生物、杀死病原体与消炎等. 在粗面 内质网中，不同浓度的次氯酸根可以导致细胞表现嗜碱 性，甚至可以引发氧化应激及氧化损伤. 粗面内质网的 次氯酸根浓度上升会导致很多人类疾病，如风湿性关节 炎、心血管疾病、动脉硬化、神经元退化甚至癌症 ${ }^{[28]}$. 因 此, 发展可以实时监测粗面型内质网中的次氯酸根的化 学工具非常重要. 常见的次氯酸根探针由于大都含有喹 啉醛、硫醇和硫酮，容易被其他活性氧物种如过氧化氢 和单线态氧所影响, 而且由于人们对弱碱性环境的忽 视，这些探针很难检测到产生于粗面内质网上的次氯酸 根.

苂光逻辑门是一种可以提供多线程生物检测的技 术，基于此技术设计的探针可以具有区分性地检测次氯 酸根及其他相关性物种. Guo 小组 ${ }^{[29]}$ 设计的探针 21 对于 不同比例的输入物会给出不同的荧光信号, 可以用做比 率苂光探针. 在此探针结构中, 丙二腈部分可以特异性 识别次氯酸根, 酰胺部分遇水会产生苂光信号的改变. 该探针可定位于粗面内质网的弱碱性环境中, 实现对粗 面内质网的苂光成像.<smiles>CCCN(C)c1ccc2cc(C=C(C#N)C#N)ccc2c1</smiles>

过氧化氢是人体内关键的活性氧物质之一, 参与了 
各种生理和病理过程, 包括细胞增殖、分化和迁移等. 新的研究表明过氧化氢在细胞内的位置决定了它在众 多生理过程中所起的不同作用. 例如, 当蛋白质在内质 网中发生错误折叠并且累积时, 内质网的内环境稳态就 会被破坏, 过氧化氢会积累并氧化细胞内蛋白质, 从而 造成损害. 它甚至可以通过切割内质网中的 Caspase-12 引起细胞凋亡, 导致神经退行性疾病、心血管疾病、代 谢性疾病和癌症等疾病 ${ }^{[30]}$. Zhang 小组 ${ }^{[31]}$ 基于 $\alpha$-酮酰胺 和荎二甲酰亚胺的化学性质, 设计了一种简单有效, 具 有特定 $\alpha$-酩酰胺识别基团的探针 $22(\alpha-N a p h)$. 探针本身 呈蓝色, 可以定量地与过氧化氢反应, 所得产物呈绿色, 故可以设计成比率苂光探针. 细胞内绿色和蓝色荧光信 号的比率与探针浓度和环境无关, 可以精确并定量地测 量内质网中的过氧化氢的浓度. 探针的检测限低至 38 $\mathrm{nmol} / \mathrm{L}$.

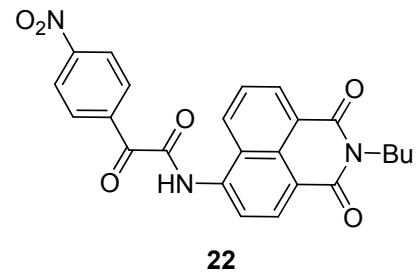

唐波小组 ${ }^{[32,33]}$ 合成了可以定位于内质网并且检测 过氧化氢的双光子探针 23a. 其由三部分组成, 1,8-萗二 甲酰亚胺是一个性能良好的荧光团, 硼酸酯是过氧化氢 的识别基团, 对甲基苯磺酰胺基团则用以定位内质网. 探针 23a 可以特异性地检测过氧化氢, 检测机理是过氧 化氢将嗍酸酯氧化水解后, 影响了分子内电荷转移过 程，导致荧光发射波长改变. 该探针颜色会随过氧化氢 的加入而改变, 加入过氧化氢后, 探针溶液由无色转变 为黄色，相应的苂光发射峰由 $458 \mathrm{~nm}$ 红移到 $558 \mathrm{~nm}$ 红 移, 量子产率由 0.007 增大到 0.24 . 当加入 $200 \mu \mathrm{mol} / \mathrm{L}$ 过氧化氢后, $558 \mathrm{~nm}$ 处的苂光强度为原来的 19 倍. 该探 针属于比率型荧光探针, 特异性好, 不与其他金属离子 或氧化剂反应. 该小组合成的另一种探针 $23 \mathrm{~b}$ 将识别基 团换成了苯并噻唑啉, 可以特异性检测超氧离子, 检测 机理是超氧离子将噻唑啉环脱氢, 从而扩大共轭体系, 氧化产物的苂光强度增强. 此探针定位性能好, 检测限 低至 $60 \mathrm{nmol} / \mathrm{L}$, 可以很好地研究内质网应激过程中超 氧离子浓度的变化.

\subsection{3 检测活性氮物种}

一氧化氮被还原会产生亚硝酰氢, 是一种活性氮物 种, 与众多心血管疾病如动脉粥样硬化、心绞痛等有着 密不可分的联系. 但由于亚硝酰氢活性高, 在生物体内 极易, 脱水二聚形成一氧化二氮, 无法有效实现对亚硝
酰氢的实时监测 ${ }^{[34]}$.

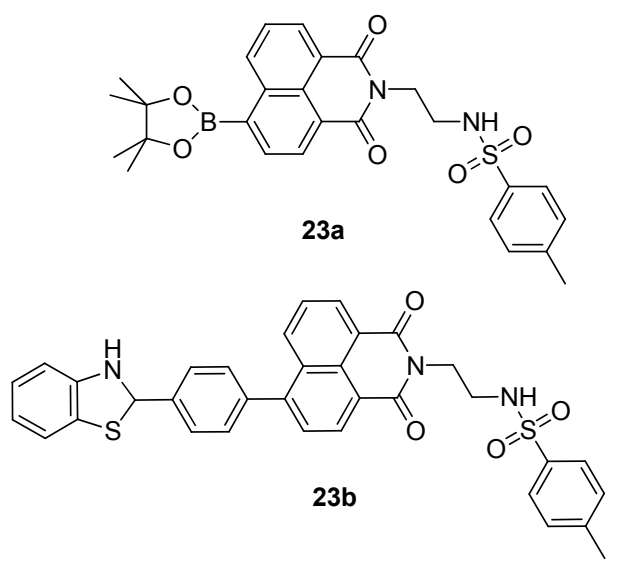

陈令新小组 ${ }^{[35]}$ 合成了一种特异性检测亚硝酰氢的 探针 24. 此探针分为三部分, 苂光团为氟嗍吡咯, 检测 基团为三苯基膦，定位基团为长烷基链. 三苯基膦基团 可与 $\mathrm{HNO}$ 反应生成氮叶立德中间体，氮叶立德继而与 分子内的酯基发生亲核反应生成酰胺，脱除后释放出苂 光团氮杂氟硼吡咯, 使得探针的荧光辐射恢复. 亚硝酰 氢浓度越大, 氟嗍吡咯荧光越强. 定位机理利用了内质 网膜的脂溶性，探针结构中的长烷基链插入了内质网膜 中.

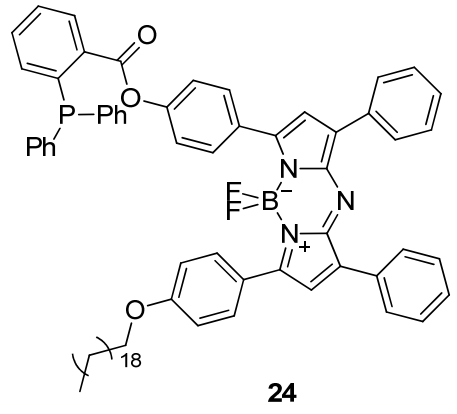

\section{1 .4 检测酶类与其他}

内质网氨肽酶 1 (ERAP1)是属于 $\mathrm{M} 1$ 肽酶家族的金 属肽酶, 在体内抗原加工过程中负责修饰作为 $\mathrm{T}$ 细胞靶 标的多肽. ERAP1 分泌紊乱可能会引起许多疾病 ${ }^{[36,37]}$. 传统的监测 ERAP1 活性的方法是使用亮氨酸-7-氨基-5甲基香豆素(L-Amc)作为酶底物，但是该方法需要破坏 细胞膜把 ERAP1 提取出来, 实际操作较为复杂. Huan 小组 ${ }^{[38]}$ 设计合成了一种基于分子内电荷转移原理的内 质网双光子荧光探针 25 (SNCL). 该探针含有 1,8-菜二 甲酰亚胺(双光子苂光团, 光学性能优良, 双光子吸收 截面大)、 $L$-亮氨酸(识别基团)和对甲基苯磺酰胺(内质网 靶向基团). 其定位与发光机理是, ERAP1 可以裂解探针 25 中的亮氨酸残基, 从而释放出荧光团部分, 使其荧光 恢复. 


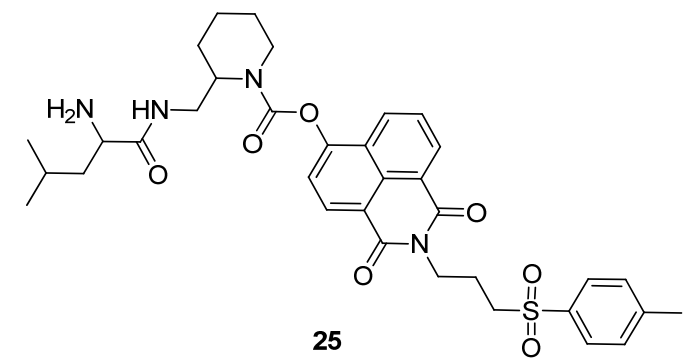

内源性硫化氢作为气体信号分子参与众多生理过 程, 在细胞器中, 特别是内质网中, 扮演着细胞代谢中 的重要角色 ${ }^{[39]}$. 林伟英小组 ${ }^{[40]}$ 合成了一种靶向内质网 中硫化氢的荧光探针 $26\left(\mathrm{Na}-\mathrm{H}_{2} \mathrm{~S}-\mathrm{ER}\right)$, 该探针信号强, 选择性好, 可以在活细胞甚至活组织和活体中进行内质 网中内源或外源硫化氢的检测成像. 探针由苂光基团 1,8-䒬二甲酰亚胺、硫化氢识别基团叠氮基团和靶向定 位内质网上钾离子通道蛋白的对甲基苯磺酰胺基团组 成. 将强吸电子叠氮基团直接连接到菜酰亚胺荧光团 上, 探针的电子结构为 “A- $\pi$ - A ” . 这种电子结构使得 荧光探针具有弱荧光发射信号. 当用硫化氢处理探针 后, 叠氮基团变成氨基基团, 由于氨基是强电子给体, 所以探针的电子结构变成 “D- $\pi-A$ ”. 由于分子内电荷 转移(ICT) 效应, 苂光探针分子具有强烈的荧光发射. 该 探针的最大吸收波长在约 $385 \mathrm{~nm}$, 随着硫化氢浓度的 增加, 探针在 $385 \mathrm{~nm}$ 处的吸收值逐渐减小, $440 \mathrm{~nm}$ 处的 吸收值逐渐增大. 类似于吸收光谱, 探针 26 的荧光发射 光谱也显著改变, 当用硫化钠(硫化氢释放剂)滴定时, 在 $545 \mathrm{~nm}$ 处观察到显著的苂光开启响应. 实验证明探 针在 $\mathrm{pH}=4 \sim 10$ 的范围内的荧光强度几乎没有变化, 同 时也具有光稳定性. 共定位实验中此探针对内质网的 Person 系数为 0.91 , 显示探针具有良好的内质网靶向性. 另外, 探针 26 还具有良好的双光子成像特性, 在活细胞 中进行硫化氢实时成像的效果十分理想(图 3). Blum 小 组 ${ }^{[41]}$ 设计了一种基于苂光猝灭原理的苂光探针族, 此 类探针与受体蛋白酶结合后, 猝灭基团离去, 从而使苂 光恢复. 可以用来检测细胞调亡时内质网中 Caspase-3 酶的活性. 由于癌细胞中 Caspase-3 酶会在内质网和线 粒体中聚集, 所以该探针可以定位到内质网或者线粒体 上. 其通式如图 4. 其中, 探针 27 对内质网定位效果好, 未与靶蛋白酶结合前几乎没有背景辐射, 结合后苂光复 现, 具有较好的应用前景.

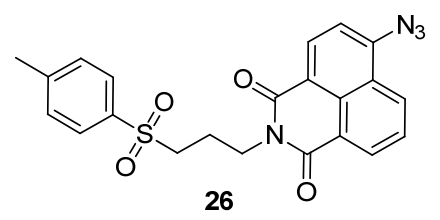

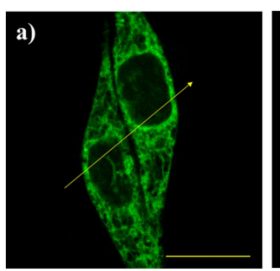
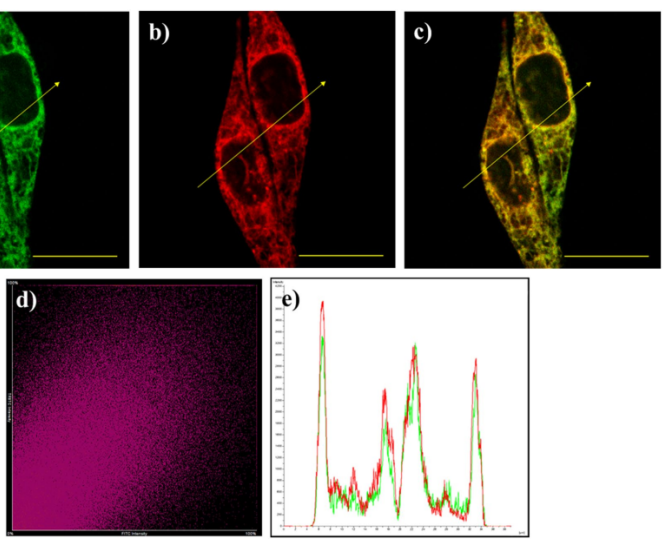

图 $3 \mathrm{HeLa}$ 细胞与探针 $\mathbf{2 6}\left(\mathrm{Na}-\mathrm{H}_{2} \mathrm{~S}-\mathrm{ER}\right) 、 \mathrm{Na}_{2} \mathrm{~S}$ 以及 ER-Tracker TM Red 的共孵育图像 ${ }^{[40]}$

Figure 3 Images of the living HeLa cells co-incubated with the probe $\mathrm{Na}-\mathrm{H}_{2} \mathrm{~S}-\mathrm{ER}, \mathrm{Na}_{2} \mathrm{~S}$ and ER-Tracker TM Red<smiles>COc1cc(N=Nc2ccc([N+](=O)[O-])cc2)c(OC)c(Nc2cc3c4c(c2)CCCN4CCC3)c1OCCCCC(=O)NCC(=O)OCC(=O)C(CC(=O)O)NC(=O)C(Cc1ccccc1)NC(=O)C(CCC(=O)O)NC(C)(C)C</smiles><smiles>N=COCCC(CCC(=O)O)C(=O)NC(Cc1ccccc1)C(=O)NC(CC(=O)O)C(=O)OCC(=O)ONCOCCN</smiles>

图 4 靶向 caspase- 3 的探针族结构通式

Figure 4 General structure of probes towards caspase-3

\section{2 检测内质网形态}

内质网主要由核膜、核周内质网和周边内质网组成. 从形态角度来说，内质网可分为管状和片状两种结构. 由于内外核膜间的距离较为恒定, 核膜通常被看作片状 结构. 在细胞核周边, 仍以表现为扁平膜囊形式的片状 内质网为主; 而在细胞外周, 则以纵横交错的网络型管 状内质网为主. 形态不同的内质网组分在细胞内承担着 不同的生理功能, 还具有调控代谢的作用. 不同细胞内 的内质网形态也会有所不同. 内质网还是一个高度动态 的膜系. 有报道表明, 在细胞有丝分裂过程中会发生片 状内质网和管状内质网的相互转化. 更重要的是, 许多 严重疾病, 如遗传性痉挛性截痽这类人类神经退行性疾 病, 与内质网形态的完整性直接相关. 因此对内质网形 态的全方位实时观测具有深刻的现实意义. 
基于内质网容易被亲脂性染料染色的特性，市面 上已经开发了包括 $\mathrm{DiOC}_{6}$ 和 $\mathrm{DiOC}_{5}$ 在内的一系列亲脂 性苂光探针, 可以用来检测内质网的形态. 然而, 这些 探针受到诸如光学稳定性不够, 荧光发射谱带较宽, 低 选择性和对其他细胞器的非特异性定位等局限性的困 扰. 一种可靠的内质网荧光探针, 应当具有较窄的发射 光谱, 较高的定位灵敏度, 持久的光稳定性和生物稳定 性以及对各种生物环境的不敏感性. 内质网应激是内质 网的病变过程, 往往伴随着内质网形态的改变. 对于内 质网应激过程中, 内质网形态的研究有助于对内质网应 激的进一步理解. Kim 小组 ${ }^{[42]}$ 设计了一种符合上述要求 的内质网选择性探针 28 (ERp), 在远红区具有尖锐的荧 光发射峰, 在生物环境中具有高稳定性, 可以监测内质 网在各种应力模式下的内质网动力学. 由于激发时不存 在电荷分离现象, 该探针成为对环境极性不明显的理想 探针. 该探针对 $\mathrm{pH}$ 和溶剂极性不敏感, 在乙腈中, 探针 28 在 $600 \mathrm{~nm}$ 附近有广泛吸收带, 在 $653 \mathrm{~nm}$ 处有强而窄 的发射峰, 使得探针 $\mathbf{2 8}$ 可以用于细胞成像. 将该探针和 不同的细胞器标记物进行共定位成像实验, 与内质网标 记物的共定位效果最好, Pearson 相关系数为 0.81 , 与其 他细胞器标记物共定位成像的 Pearson 相关系数低, 表 明其选择性定位于内质网. 探针 28 可以用来演示由内 质网应激诱导因子衣霉素引起的内质网在细胞核周围 区域的快速重组, 对于研究内质网应激过程有重要意义 (图 5).

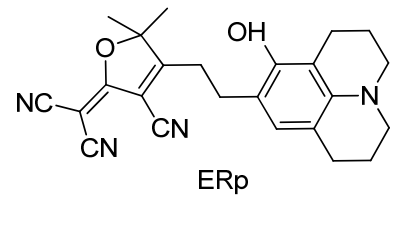

28

\section{3 检测内质网的化学环境}

内质网中部分未折叠或糖基化蛋白质的积累会导 致内质网应激状态的形成, 从而引发内质网粘度和极性 的改变. 而内质网应激状态的活动在诸如糖尿病、阿兹 海默症等疾病中影响显著. 因此, 监测并预测内质网应 激状态粘度和极性的变化是十分有意义的.

随着生物传感技术的发展, 已开发出多种荧光化学 传感器, 用来测量生物粘度或极性. 对于粘度测量, “分子转子”已经被开发用于苂光比率成像或苂光寿 命成像技术. Kim 小组 ${ }^{[43]}$ 合成的一种新型双荧光团探针 29, 由氟硼吡咯和尼罗红(Nile-Red)组成. 氟硼吡咯部 分相当于分子转子, 自由旋转时无荧光, 体系粘度增大, 自由旋转被抑制, 荧光强度随之增大. 尼罗红则是极性 敏感探针, 极性越大荧光强度越低, 且吸收发射波长红
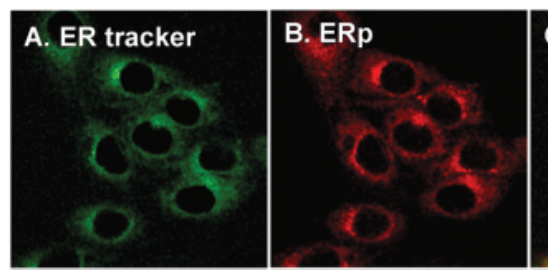

C. Merged $(A+B)$
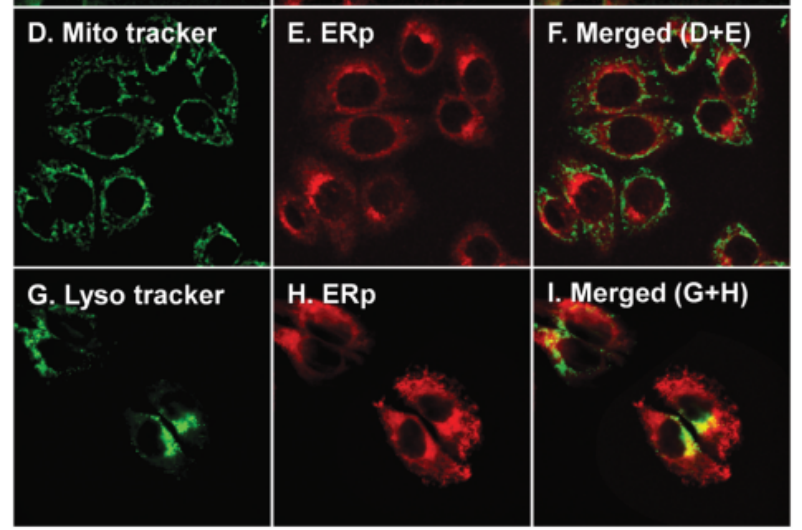

图 5 在 Hela 细胞中探针 28 (ERp) 与各种细胞器特异性标记 物的共定位实验 ${ }^{[42]}$

Figure 5 Co-localization experiment of probe 28 (ERp) with various organelle-specific markers in Hela cells.

移. 共定位实验表明探针定位在内质网上，可以通过测 定 575 和 $625 \mathrm{~nm}$ 处荧光强度的比率以及 $516 \mathrm{~nm}$ 处荧光 寿命来测定内质网膜的极性和粘度.

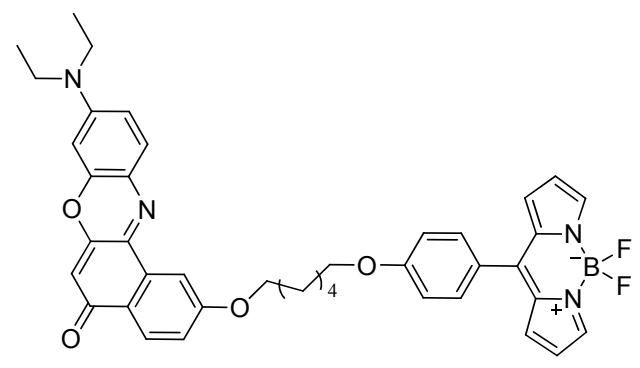

29

该小组 ${ }^{[44]}$ 设计了另外一种以尼罗红和氟硼吡咯为 基础的内质网膜流动性探针 30. 尼罗红吸收峰受环境 极性影响较大, 在测量荧光强度时会产生较大误差, 因 此用氟嗍吡咯作为荧光共振能量转移的给体以稳定对 尼罗红的激发. 此探针苂光强度与探针浓度无关, 且特 异定位在内质网膜上, 定位机理主要利用了尼罗红的脂 溶性，探针尼罗红部分嵌入脂膜中，而聚乙二醇部分裸 露在外. 探针 30 的光谱性质与溶液环境极性有关, 在 495 和 $530 \mathrm{~nm}$ 处有吸收峰, 分别对应于尼罗红和氟硼 吡咯各自的吸收峰; $612 \mathrm{~nm}$ 处有发射峰, 是尼罗红基团 在疏水环境中的特异性苂光发射. 该探针发射峰对膜流 动性敏感，随着膜的流动性减弱探针发射峰蓝移. 


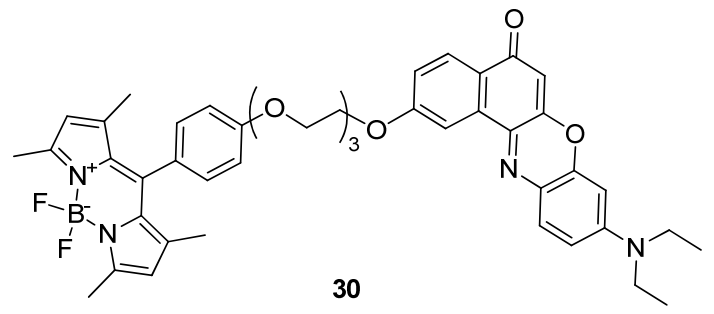

Chang 小组 ${ }^{[45]}$ 合成了 BDNCA346 温度传感探针 31, 又称作 ER thermo yellow, 此探针荧光强度随温度升高 而下降, 且特异性定位在内质网(图 6). 其耐光性和亮度 良好, 吸收峰和发射峰分别为 559 和 $581 \mathrm{~nm}$. 当使用探 针 31 进行表征时, 观测到了内质网中钲离子热激活过 程所导致的内质网局部温度的微小变化.<smiles></smiles>
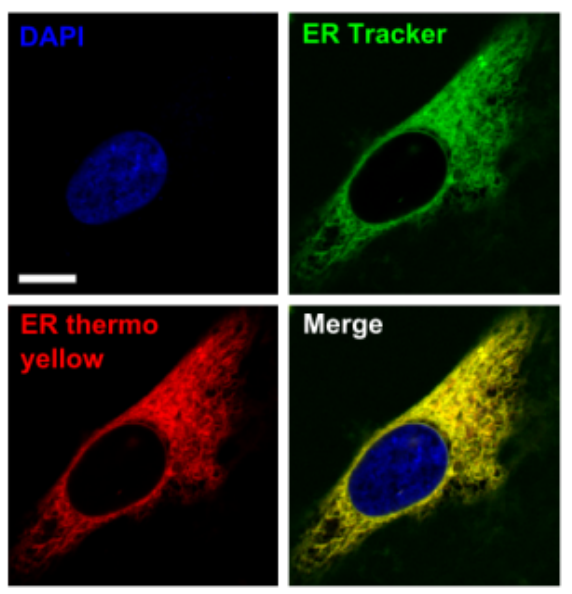

图 6 内质网靶向的荧光温度探针 $31^{[45]}$

Figure 6 ER targetable fluorescent thermometer $31^{[45]}$

通常测定 $\mathrm{pH}$ 是基于发色团自身的光谱在不同 $\mathrm{pH}$
下荧光强度不一样的原理, 但发色团波长常常在比较低 的波段, 且自身荧光和周边生物环境会产生很大的干扰 使信噪比很低. 为了克服这种缺点, Parker 小组 ${ }^{[46]}$ 设计 了一个以 $\mathrm{Eu}(\mathrm{III})$ 为内核, 并利用延时发光技术的探针 32, 因为其光学性质和发射状态取决于配位环境, $\mathrm{pH}$ 不 同会导致其荧光强度和激发态寿命的改变。与 ER-Tracker 共定位实验发现其定位于内质网，可以用以 检测内质网中 $\mathrm{pH}$ 的变化.

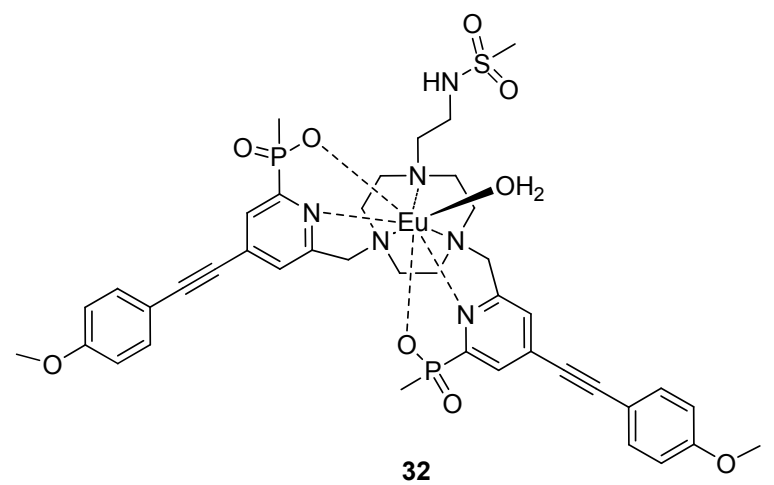

\section{3 总结与展望}

在之前的综述中, 我们总结与评述了近些年来线粒 体探针和溶酶体探针的研究进展 ${ }^{[47,48]}$, 本文介绍了数十 种定位内质网的单功能探针和定位并检测内质网内活 性物种以及内质网环境的多功能探针. 内质网探针定位 机理大致可以分为三种: 基于内质网代谢过程, 基于与 内质网中特异性物种结合, 以及基于内质网膜的脂溶 性. 目前种类最多且发展较完善的是可以检测内质网内 特殊活性物种的苂光探针. 这些探针往往由一个定位基 团和一个荧光/检测基团组成, 且探针整体为偏脂溶性 的分子. 利用比率苂光等技术可以实现对内质网形态以 及内质网化学环境的检测. 本文中所讨论的探针分子总 体情况如表 1 所示, 这些探针对于研究内质网正常生理 状态和环境, 以及发生内质网应激时的生理状态和环境 变化具有重要意义, 为防治由内质网应激引起的各类疾 病提供了重要理论参考. 总的来说, 目前多功能内质网

表 1 内质网探针汇总

Table 1 Summary of ER probe

\begin{tabular}{cllcc}
\hline 探针 & 苂光团 & \multicolumn{1}{c}{ 定位机理 } & 探针功能 & 文献 \\
\hline $\mathbf{1}$ & 苯并呋咱 & 内质网代谢 & 定位于内质网 & {$[8]$} \\
$\mathbf{2}$ & 试卤灵 & 内质网代谢 & 定位于内质网 & {$[10]$} \\
$\mathbf{3}$ & 氟硼荧 & 与内质网中特异性物质结合 & 定位于内质网 & $-_{a}$ \\
$\mathbf{4}$ & 芴 & 与内质网中特异性物质结合 & 定位于内质网 & {$[11]$} \\
$\mathbf{5}$ & 黄酩 & 与内质网中特异性物质结合 & 定位于内质网 & {$[12]$} \\
$\mathbf{6 \sim 7}$ & 四苯乙烯 & 与内质网中特异性物质结合 & 定位于内质网 & {$[13]$} \\
$\mathbf{8 \sim 9}$ & 菁 & 内质网脂溶性 & 定位于内质网 & $-a$ \\
$\mathbf{1 0}$ & 试卤灵 & 内质网脂溶性 & 定位于内质网 & {$[14]$} \\
\hline
\end{tabular}


续表

\begin{tabular}{|c|c|c|c|c|}
\hline 探针 & 荧光团 & 定位机理 & 探针功能 & 文献 \\
\hline 11 & 氧杂葱 & 内质网脂溶性 & 定位于内质网 & {$[15]$} \\
\hline 12 & 方酸染料 & 内质网脂溶性 & 定位于内质网 & {$[16]$} \\
\hline 13 & 氮杂氟硼苂 & 内质网脂溶性 & 定位于内质网 & {$[17]$} \\
\hline 14 & 铱配合物 & 内质网脂溶性 & 定位于内质网 & {$[18]$} \\
\hline 15 & 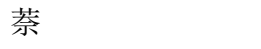 & 定位机理不明 & 定位于内质网 & [19] \\
\hline 16 & 苂光氨基酸小分子 & 非天然氨基酸标记技术 & 定位于内质网 & {$[20]$} \\
\hline 17 & 苯并噻唑 ～～～～～ & 内质网脂溶性 & 定位并检测锌离子 & {$[22]$} \\
\hline 18 & 试卤灵 & 与内质网中特异性物质结合 & 定位并检测锌离子 & {$[23,24]$} \\
\hline 19 & 罗丹明 ～～～～～～～～ & 定位机理不明 & 定位并检测金属离子 & {$[26]$} \\
\hline 20 & 萗二甲酰亚胺 & 定位机理不明 & 定位并检测金属离子 & {$[27]$} \\
\hline 21 & 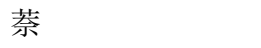 & 内质网内环境 & 定位并检测次氯酸根 & [29] \\
\hline 22 & 萗二甲酰亚胺 & 定位机理不明 & 定位并检测活性氧物种 & {$[31]$} \\
\hline 23 & 萗二甲酰亚胺 & 与内质网中特异性物质结合 & 定位并检测活性氧物种 & {$[32,33]$} \\
\hline 24 & 氮杂氟硼菼 & 内质网脂溶性 & 定位并检测活性氮物种 & {$[35]$} \\
\hline 25 & 慕二甲酰亚胺 & 与内质网中特异性物质结合 & 定位并检测酶 & {$[38]$} \\
\hline 26 & 慕二甲酰亚胺 & 与内质网中特异性物质结合 & 定位并检测硫化氢 & {$[40]$} \\
\hline 27 & 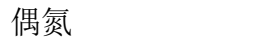 & 与内质网中特异性物质结合 & 定位并检测酶 & {$[41]$} \\
\hline 28 & 丙二腈衍生物 & 定位机理不明 & 定位并检测内质网形态 & {$[42]$} \\
\hline 29 & 氟硼吡咯-尼罗红 & 内质网脂溶性 & 检测内质网内环境 & [43] \\
\hline 30 & 氟嗍吡咯-尼罗红 & 内质网脂溶性 & 检测内质网内环境 & {$[44]$} \\
\hline 31 & 氟嗍菼 ～～～～～～ & 与内质网中特异性物质结合 & 定位并检测内质网温度 & {$[45]$} \\
\hline 32 & 铕配合物 & 与内质网中特异性物质结合 & 定位并检测内质网 pH & [46] \\
\hline
\end{tabular}

${ }^{a}$ Commercially available fluorescent probe.

探针的研究还有待于进一步深入和完善, 有些报道的内 质网苂光探针的定位机理仍然不清楚. 作为一种重要的 研究工具, 内质网探针在医学、生理学和细胞生物学等 众多学科和临床治疗中有着越来越广阔的应用前景.

\section{References}

[1] Ling, Y.-P.; Yu, Z. Cellular Ultrastructure and Electron Microscope Technology-Fundamentals of Molecular Cell Biology, Fudan University Press, Shanghai, 2000, pp. 29 33 (in Chinese).

(凌诒萍, 俞彰主编, 细胞超微结构与电镜技术, 分子细胞生物 学基础, 复旦大学出版社, 上海, 2000, pp. 29 33.)

[2] Liu, L.-Y. Cell Biology, Higher Education Press, Beijing, 2002, pp. 79 84 (in Chinese). (刘凌云主编, 细胞生物学, 高等教育出版社, 北京, 2002, pp. $79 \sim 84$.)

[3] Fang, H.; Shen, Z.-H. J. Med. Mol. Biol. 2004, 1, 36 (in Chinese) (方欢，申宗侯，医学分子生物学杂志, 2004, 1, 36)

[4] Samali, A.; Fitzgerald, U.; Deegan, S.; Gupta, S. Int. J. Cell Biol. 2010, 830307.

[5] Chen, N.-Z.; Jiang, C.; Li, X.-K. Chin. Biotechnol. 2016, 36, 76 (in Chinese). (陈娜子，姜潮，李校㫃，中国生物工程杂志, 2016, 36, 76.)

[6] (a) Li, N. Fluorescent Probe Application Technology, Military Medical Science Press, Beijing, 1998, pp. 11 13 (in Chinese). (李楠, 荧光探针应用技术, 军事医学科学出版社, 北京, 1998, pp. $11 \sim 13$.)

(b) Xie, Z.; Fu, M.; Yin, B.; Zhu, Q. Chin. J. Org. Chem. 2018, 38, 1364 (in Chinese) (谢振达，付曼琳，尹虎，朱勍，有机化学, 2018, 38, 1364.)

[7] Terasaki, M.; Song, J.-D.; Wong, R. James.; Chen, L,-B. Cell 1984, 38,101 .

[8] Villa, A.; Caporizzo, E.; Papagni, A.; Miozzo, L.; Buttero, P.; Grilli, M.; Amboldi, N.; Fazio, F.; Doglia, S.; Giglioni, B. Eur. J. Cancer $\mathbf{2 0 0 5}, 41,1453$.

[9] Imai, T.; Hosokawa, M. J. Pestic. Sci. 2010, 35, 229.

[10] Hakamata, W.; Machida, A.; Oku, T.; Nishio, T. Bioorg. Med. Chem. Lett. 2011, 21, 3206.

[11] Zhang, H.; Fan, J.-L.; Dong, H.-J.; Zhang, S.-Z.; Xu, W.-Y.; Wang, J.-Y.; Gao, P.; Peng, X.-J. J. Mater. Chem. B 2013, 1, 5450.

[12] McDonald, L.; Liu, B.; Taraboletti, A.; Whiddon, K.; Shriver, L. Konopka, M.; Liu, Q.; Pang, Y. J. Mater. Chem. B 2016, 4, 7902.

[13] Zhang, C.-J.; Cai, X.-L.; Xu, S.-D.; Zhan, R.-Y.;Wu J.-E.; Liu, B. Chem. Commun. 2017, 53, 10792.

[14] Phaniraj, S.; Gao, Z.; Rane, D.; Peterson, B. Dyes Pigm. 2016, 135, 127.

[15] Meinig, M.; Fu, L.-Q.; Peterson, B. Angew. Chem., Int. Ed. 2015 , 54, 9696.

[16] Collot, M.; Kreder, R.; Tatarets, A.; Patsenker, L.; Melya, Y.; Klymchenko, A. Chem. Commun. 2015, 51, 17136.

[17] Kamkaew, A.; Thavornpradit, S.; Puangsamlee, T.; Xin, D.-Y.; Wanichachevab, N.; Burgess, K. Org. Biomol. Chem. 2015, 13, 8271.

[18] Anjog, T.; Kim, G.; Jang, H.-Y.; Yoon, J.; Kim, J. New J. Chem. 2017, 41, 377 .

[19] Lee, H.-W.; Cho, M.-K.; Kim, H.-R.; Lim, C.-S.; Kang, C.; Kim, H.-M. Chem. Commun. 2017, 53, 6097.

[20] Chatterjee, A.; Guo, J.; Lee, H.; Schultz, P. J. Am. Chem. Soc. 2013, 135,12540 .

[21] Takeda, A. Brain Res. Rev. 2000, 34, 137

[22] Gan, X.-P.; Sun, P.; Li, H.; Tian, X.-H.; Zhang, B.-W.; Wu, J.-Y.; Tian, Y.-P.; Zhou, H.-P. Biosens. Bioelectron. 2016, 86, 393.

[23] Loas, A.; Radford, J. R.; Lippard, J. S. Inorg. Chem. 2014, 53, 6491.

[24] Lin, W.; Buccella, D.; Lippard, J. S. J. Am. Chem. Soc. 2013, 135, 13512

[25] Ganz T. J. Am. Soc. Nephrol. 2007, 18, 394

[26] Lee, M. H.; Lee, H.; Chang, M. J.; Kim, H. S.; Kang, C.; Kim, J. S. Dyes Pigm. 2016, 130, 245. 
[27] Park, S. Y.; Kim, W.; Park, S.-H.; Han, J.; Lee, J.; Kang, C.; Lee, M. H. Chem. Commun. 2017, 53, 4457.

[28] Dimenico, L.; Franco, C. Gen. Pharmacol. 1996, 27, 1145.

[29] Li, J.-P.; Xia, S.; Zhang, H.; Qu, G.-R.; Guo, H.-M. Sens. Actuators $B$ 2018, 255, 622 .

[30] Kong, M.; Chen, J.; Zhou, J.; Zhu, W.-D.; Wan, L.-M.; Xiong, Y.-F.; Li, Z.-X. Acta Med. Univ. Sci. Technol. Huazhong 2012, 41, 253 (in Chinese).

(孔曼, 陈娟, 周洁, 朱文德, 万丽敏, 熊宇芳, 李子希, 华中科 技大学学报医学版, 2012, 41, 253.)

[31] Gao, C.-C.; Tian, Y.; Zhang, R.-B.; Jing, J.; Zhang X.-L. Anal. Chem. 2017, 89, 12945.

[32] Xiao, H.-B.; Liu, X.; Wu, C.-C.; Wu, Y.-H.; Li, P.; Guo, X.-M.; Tang, B. Biosens. Bioelectron. 2017, 91, 449.

[33] Xiao, H.-B.; Li, P.; Hu, X.-F.; Shi, X.-H.; Zhang, W.; Tang, B. Chem. Sci. 2016, 7, 6153.

[34] Irvine, J. C.; Ritchie, R. H.; Favaloro, J. L.; Andrews, K. L.; Widdop, R. E.; Kemp-Harper, B. K. Trends Pharmacol. Sci. 2008, 29, 601 .

[35] Liu, P.; Han, X.-Y.; Yu, F.-B.; Chen, L.-X. Chin. J. Anal. Chem. 2015, 43, 1829 (in Chinese). (刘萍, 韩潇玥, 于法标, 陈令新, 分析化学, 2015, 43, 1829.)

[36] Fruci, D.; Ferracuti, S.; Limongi, M. Z.; Cunsolo, V.; Giorda, E.; Fraioli, R.; Sibilio, L.; Carroll, O.; Hattori, A.; van Endert, P. M.; Giacomini, P. J. Immunol. 2006, 176, 4869.

[37] Hisatsune, C.; Ebisui, E.; Usui, M.; Ogawa, N.; Suzuki, A.; Mataga, N.; Takahashi-Iwanaga, H.; Mikoshiba, K. Mol. Cell 2015, 58,
1015.

[38] Xu, S.; Liu, H.-W.; Hu, X.-X.; Huan, S.-Y.; Zhang, J.; Liu, Y.-C.; Yuan, L.; Qu, F.-L.; Zhang, X.-B.; Tan, W.-H. Anal. Chem. 2017, 89, 7641.

[39] Olas, B. Clin. Chim. Acta 2015, 439, 212.

[40] Tang, Y.-H.; Xu, A.; Ma, Y.-Y.; Xu, G.-P.; Gao, S.-Y.; Lin, W.-Y. Sci. Rep. 2017, 7, 12944.

[41] Shaulov-Rotem, Y.; Merquiol, E.; Weiss-Sadan, T.; Moshel, O.; Salpeter, S.; Shabat, D.; Kaschani, F.; Kaiser, M.; Blum, G. Chem. Sci. 2016, 7, 1322.

[42] Kim, H.-R.; Kumar, R.; Kim, W.; Lee, J. H.; Suh, M.; Sharma, A.; Kim, C. H.; Kang, C.; Kim J. S. Chem. Commun. 2016, 52, 7134.

[43] Yang, Z.-G.; He, Y.-X.; Lee, J. H.; Chae, W.-S.; Ren, W. X.; Lee, J. H.; Kang, C.; Kim, J. S. Chem. Commun. 2014, 50, 11672.

[44] Yang, Z.-G.; Wi, Y.; Yoon, Y.-M.; Verwilst, P.; Jang, J. H.; Kim, T. W.; Kang, C.; Kim, J. S. Chem.-Asian J. 2016, 11, 527.

[45] Arai1, S.; Lee, S.-C.; Zhai, D.-T.; Suzuki, M.; Chang, Y. T. Sci. Rep. 2014, 4, 6701.

[46] McMahon, B. K.; Pal, R.; Parker, D. Chem. Commun. 2013, 49, 5363.

[47] Li, Y; Lv, Z.; Liu, M.; Xing, G. Chin. J. Org. Chem. 2016, 36, 962 (in Chinese).

(李杨洁, 吕子奇, 刘敏, 邢国文, 有机化学, 2016, 36, 962.)

[48] Li, M.; Wang, Y.; Liu, G.; Lv, H.; Xing, G. Chin. J. Org. Chem. 2017, 37, 356 (in Chinese). (李美含, 王宇童, 刘广建, 吕海娟, 邢国文, 有机化学, 2017, 37, 356.) 